\title{
A spider derived peptide, PnPP-19, induces central antinociception mediated by opioid and cannabinoid systems
}

\author{
Daniela da Fonseca Pacheco ${ }^{1}$, Ana Cristina Nogueira Freitas ${ }^{2}$, Adriano Monteiro C. Pimenta², \\ Igor Dimitri Gama Duarte ${ }^{1}$ and Maria Elena de Lima ${ }^{2 *}$
}

\begin{abstract}
Background: Some peptides purified from the venom of the spider Phoneutria nigriventer have been identified as potential sources of drugs for pain treatment. In this study, we characterized the antinociceptive effect of the peptide PnPP-19 on the central nervous system and investigated the possible involvement of opioid and cannabinoid systems in its action mechanism.
\end{abstract}

Methods: Nociceptive threshold to thermal stimulation was measured according to the tail-flick test in Swiss mice. All drugs were administered by the intracerebroventricular route.

Results: PnPP-19 induced central antinociception in mice in the doses of 0.5 and $1 \mu \mathrm{g}$. The non-selective opioid receptor antagonist naloxone $(2.5$ and $5 \mu \mathrm{g}$ ), $\mu$-opioid receptor antagonist clocinnamox (2 and $4 \mu \mathrm{g}$ ), $\delta$-opioid receptor antagonist naltrindole $\left(6\right.$ and $12 \mu \mathrm{g}$ ) and $\mathrm{CB}_{1}$ receptor antagonist AM251 (2 and $4 \mu \mathrm{g}$ ) partially inhibited the antinociceptive effect of PnPP-19 $(1 \mu \mathrm{g})$. Additionally, the anandamide amidase inhibitor MAFP $(0.2 \mu \mathrm{g})$, the anandamide uptake inhibitor VDM11 $(4 \mu \mathrm{g})$ and the aminopeptidase inhibitor bestatin $(20 \mu \mathrm{g})$ significantly enhanced the antinociception induced by a low dose of PnPP-19 $(0.5 \mu \mathrm{g})$. In contrast, the $\mathrm{k}$-opioid receptor antagonist nor-binaltorphimine $(10 \mu \mathrm{g}$ and $20 \mu \mathrm{g})$ and the $\mathrm{CB}_{2}$ receptor antagonist AM630 ( 2 and $4 \mu \mathrm{g}$ ) do not appear to be involved in this effect.

Conclusions: PnPP-19-induced central antinociception involves the activation of $\mathrm{CB}_{1}$ cannabinoid, $\mu$ - and $\delta$-opioid receptors. Mobilization of endogenous opioids and cannabinoids might be required for the activation of those receptors, since inhibitors of endogenous substances potentiate the effect of PnPP-19. Our results contribute to elucidating the action of the peptide PnPP-19 in the antinociceptive pathway.

Keywords: Peptide PnPP-19, Central antinociception, Phoneutria nigriventer, $\mu$-opioid receptor, $\delta$-opioid receptor, CB1 receptor, CB2 receptor

\section{Background}

PnPP-19 is a synthetic peptide that contains 19 amino acid residues [1]. It represents a part of the primary structure of the native toxin PnTx2-6, also known as $\delta$ ctenitoxin-Pn2a [2], which was isolated from the venom of the spider Phoneutria nigriventer [3]. Some peptides purified from the venom of this spider have been

\footnotetext{
* Correspondence: lima.mariaelena@gmail.com; melenalima@icb.ufmg.br 2Departamento de Bioquímica e Imunologia, Instituto de Ciências Biológicas, Universidade Federal de Minas Gerais (UFMG), Av. Antônio Carlos, 6627, Belo Horizonte, MG CEP 31.270.901, Brazil

Full list of author information is available at the end of the article
}

identified as potential sources of drugs for pain treatment. For example, PnTx3-3, renamed $\omega$-ctenitoxinPn2a [2], showed an antinociceptive effect in different models of neuropathic pain [4]. Additionally, Ph $\alpha 1 \beta$ neurotoxin, another toxin isolated from that same venom, induced antinociception in models of neuropathic and inflammatory pain [5].

Cannabinoids and opioids are two separate groups of psychoactive drugs that exhibit several similar pharmacological effects, including analgesia, sedation, hypothermia and inhibition of motor activity [6-8]. In recent years, our group has demonstrated the involvement of endogenous 
opioids and cannabinoids in the antinociceptive action of several substances $[9,10]$. Receptors for both drugs are coupled to similar intracellular signaling mechanisms and the interaction between cannabinoid and opioid systems in the nociceptive pathway has been the focus of much attention [9, 11-15].

Interestingly, it has been shown that endogenous opioids are involved in antinociception induced by a scorpion toxin [16]. Therefore, it is hypothesized that pain relief induced by alpha- or beta- scorpion toxins may implicate the activation of an endogenous opioid system. The analgesic effect of those toxins might be partially due to the activation of diffuse noxious inhibitory controls of supra-spinal origin, which are linked to a counter-irritation phenomenon and release of endogenous opioids [16]. Thus, opioid peptides may be involved in the action mechanism of other toxins, particularly toxins from other arthropods, such as the spider Phoneutria nigriventer.

Recently we have shown that PnPP-19 induces antinociception in the peripheral nervous system [17]. We suggested that this effect is attributable to an inhibition of the neutral endopeptidase (neprilysin), which may lead to an increase of enkephalin levels and may cause activation of both $\mu$ - and $\delta$-opioid receptors. In addition, we showed evidence that the receptor CB1 is implicated in the antinociceptive effect induced by PnPP-19.

Given the lack of information concerning the antinociceptive effect of PnPP-19 on the central nervous system (CNS), the aim of the present study was to determine the possible effect of this peptide on the CNS and investigate whether there is an involvement of the cannabinoid and opioid systems.

\section{Methods}

\section{Animals}

The experiments were performed on 25-30 g male Swiss mice ( $n=4$ per group) provided by the CEBIO ("Centro de Bioterismo", the Animal Center) of the Universidade Federal de Minas Gerais (UFMG). The mice were housed in a temperature-controlled room $\left(23 \pm 1{ }^{\circ} \mathrm{C}\right)$ on an automatic 12-h light/dark cycle (06:00-18:00 h of light phase). All tests were carried out during the light phase (08:00-15:00 h). Food and water were freely available until the onset of the experiments. The algesimetric protocol was approved by the Committee for Ethics in Animal Experimentation (CETEA) of UFMG, with the protocol number 131/2014.

\section{Algesimetric method}

The tail-flick test used in the present study was conducted in accordance with the procedure described by D'Amour and Smith [18] with a slight modification. The test consists of restraining the mouse by one of the experimenter's hands and positioning the distal portion of the mouse's tail (about $2 \mathrm{~cm}$ from the tip of the tail) under a helical nickel-chrome resistance. When the device is turned on, an electric current starts to flow through the resistance, which may lead to a rise of its temperature. In addition, the moment that the equipment is turned on, a timer is activated. The time required for the animal to perceive the nociceptive stimulus and execute the tail withdrawal reflex is measured and expressed in seconds. The intensity of the heat reached by the resistance was adjusted, so the baseline latencies required to observe the withdrawal reflex of the mouse's tail were between 3 and $4 \mathrm{~s}$ (the thermal stimulus applied increased from 0.297 calories/s). To avoid tissue damage, the cutoff time was established at $9 \mathrm{~s}$ [19]. The baseline latency was obtained for each animal before drug administration (zero time) by calculating an average of three consecutive trials. To reduce stress, mice were habituated to the apparatus one day prior to conducting the experiments.

\section{Intracerebroventricular injection (i.c.v.)}

Animals were constrained by an acrylic tube-shaped device (Insight, Brazil). To facilitate the i.c.v. injection, the animals were placed inside this tube, which immobilizes their body, except for their head. With one hand, the experimenter restrained the animal's head and then injected the drugs into its right lateral ventricle, by the intracerebroventricular route, using a Hamilton syringe of $5 \mu \mathrm{L}$. The site of injection was $1 \mathrm{~mm}$ from either side of the midline of a line drawn through the anterior base of the ears (modified from Haley and McCormick, [20]). The syringe was inserted perpendicularly through the skull into the brain at the depth of $2 \mathrm{~mm}$, and $2 \mu \mathrm{L}$ of solution was injected. To determine whether drugs were injected correctly into the brain ventricular system, they were diluted in a solution containing Evans blue 0.5\%. Once the experiment was finished, the animals were euthanized with an overdose of anesthesia and their brains were sectioned for confirmation of the side of injection.

\section{Experimental protocol}

All drugs were i.c.v. administered into the right lateral ventricle. Naloxone, clocinnamox, naltrindole, nor-binaltorphimine, AM251, AM630, MAFP, VDM11 and bestatin were administered $1 \mathrm{~min}$ prior to administration of PnPP-19. The protocol to determine the best moment for the injection of each substance was assessed in pilot experiments and literature data $[10,15]$.

The nociceptive threshold was always represented by the time, in seconds, required for the animal to exhibit the tail withdrawal reflex. The measurements were 
performed before any drug administration and after 5, 10,15 and $30 \mathrm{~min}$ after drug injection.

\section{Statistical analysis}

Data were analyzed statistically by Repeated Measures ANOVA with post-hoc Bonferroni's test for multiple comparisons. Probabilities less than 5\% $(\mathrm{p}<0.05)$ were considered to be statistically significant.

\section{Chemicals}

The following drugs and chemicals were used: PnPP-19 (synthesized by China Peptides, China), the opioid receptor antagonist naloxone (Sigma, USA), the $\mu$-opioid receptor antagonist clocinnamox (Tocris, USA), the $\delta$ opioid receptor antagonist naltrindole (Tocris, USA), the K-opioid receptor antagonist nor-binaltorphimine (Sigma, USA), the aminopeptidase inhibitor bestatin (Sigma, USA), AM251 [N-(piperidin-1-yl)-5-(4-iodophenyl)-1-(2,4-dichlorophenyl)-4-methyl-1H-pyrazole-3-carboxamide; Tocris, USA], AM630 \{6-iodo-2-methyl-1[2-(4-morpholinyl)ethyl]-1H-indol-3-yl(4-ethoxyphenyl) methanone; Tocris, USA $\}, \quad$ MAFP $[(5 Z, 8 Z, 11 Z, 14 Z)-$ 5,8,11,14-eicosatetraenyl-methyl ester phosphonofluoridic acid, Tocris, USA $]$ and VDM11 $[(5 Z, 8 Z, 11 Z, 14 Z)-N-(4-$ Hydroxy-2-methylphenyl)-5,8,11,14-eicosatetraenamide,

Tocris, USA].

The drugs were dissolved as follows: PnPP-19 (saline), naloxone (saline), clocinnamox (saline), naltrindole (saline), nor-binaltorphimine (saline), bestatin (saline), AM251 and AM630 (12\% DMSO in saline), MAFP (10\% DMSO in saline), VDM11 (10\% in saline) and injected at a volume of $2 \mu \mathrm{L}$ into the lateral ventricle. The saline used for dilution of all drugs contained 0.5\% Evans Blue.

\section{Results}

\section{Antinociceptive effect of PnPP-19}

Since the peptide PnPP-19 is known to induce peripheral antinociception, we decided to investigate whether it could also interact with the central nervous system and induce antinociception mediated by activation of central signaling related to the nociceptive pathway [17]. Firstly, PnPP-19 was injected intracerebroventricularly. Then it was observed that the doses of 0.5 and $1 \mu \mathrm{g} / \mathrm{per}$ animal induced a significant delay of the tail withdraw reflex of the mice. This result may indicate that at those doses, PnPP-19 leads to an antinociceptive response in a dose-dependent manner (Fig. 1). The dose of $0.25 \mu \mathrm{g} /$ per animal was ineffective whereas the control group of mice injected only with vehicle (saline) remained unaltered. The dose of $1 \mu \mathrm{g}$ was chosen for the following experiments in the present study since it had almost reached the cutoff time of the test $(9 \mathrm{~s})$.

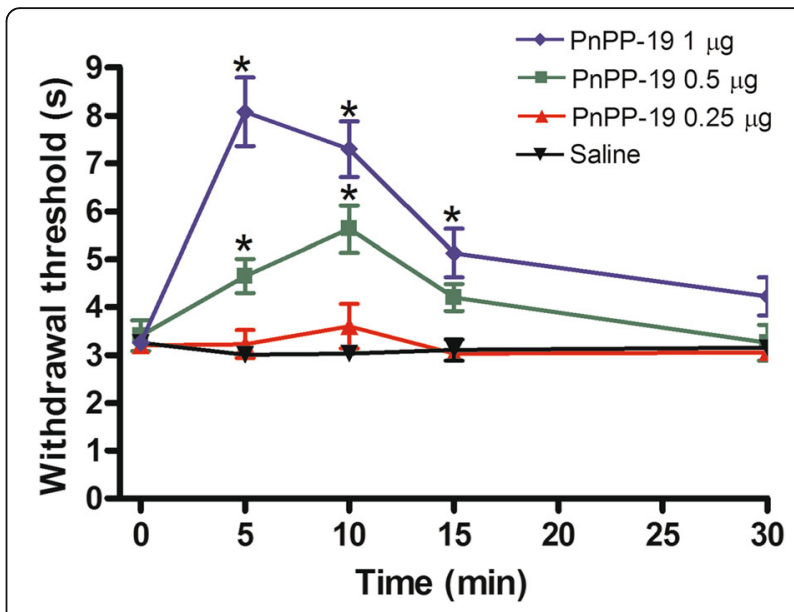

Fig. 1 Central antinociception induced by intracerebroventricular administration of PnPP-19 in mice. PnPP-19 $(0.25,0.5$ and $1 \mu \mathrm{g})$ was administered 5 min prior measurement in the tail-flick test. Each line represents the mean \pm SEM for four mice per group. *Significant difference compared to the Saline-injected group (ANOVA + Bonferroni test, $p<0.05)$. Saline (0.5\% of Evans Blue)

\section{Antagonism of PnPP-19-induced antinociception by naloxone, clocinnamox, naltrindole and AM251}

To investigate whether opioid or cannabinoid receptors were involved in PnPP-19-induced antinociception, the peptide was co-administered with non-specific and specific opioid antagonists and also with specific cannabinoid antagonists. As shown in Fig. 2, the intracerebroventricular administration of naloxone (2.5 and $5 \mu \mathrm{g})$ (Fig. 2a), clocinnamox (2 and $4 \mu \mathrm{g})$ (Fig. 2b), naltrindole (6 and $12 \mu \mathrm{g})$ (Fig. 2c) and AM251 (2 and $4 \mu \mathrm{g}$ ) (Fig. 2d) partially inhibited the antinociceptive response induced by $1 \mu \mathrm{g}$ of PnPP-19. Taken together, these data suggest the participation of $\mu$ - and $\delta$-opioid receptors and the $\mathrm{CB}_{1}$ cannabinoid receptor in the effect elicited by the peptide. The highest effective dose of the antagonists did not significantly modify the nociceptive threshold in control groups (Fig. 2a, b, $c$ and $d)$.

\section{Effect of nor-binaltorphimine and AM630 on PnPP19-induced antinociception}

The intracerebroventricular administration of norbinaltorphimine (10 and $20 \mu \mathrm{g})$ and AM630 (2 and $4 \mu \mathrm{g})$ did not block the central antinociception of PnPP-19 $(1 \mu g$; Fig. 3a and b), suggesting that the activation of either $\mathrm{k}$-opioid receptors or $\mathrm{CB}_{2}$ cannabinoid receptors does not contribute to the peptide's effect on the central nociceptive pathway. These drugs did not significantly modify the nociceptive threshold in control groups.

Increase of PnPP-19-induced antinociception by bestatin, MAFP and VDM11

Because PnPP-19 induces activation of both opioid and cannabinoid receptors, we used the aminopeptidase 

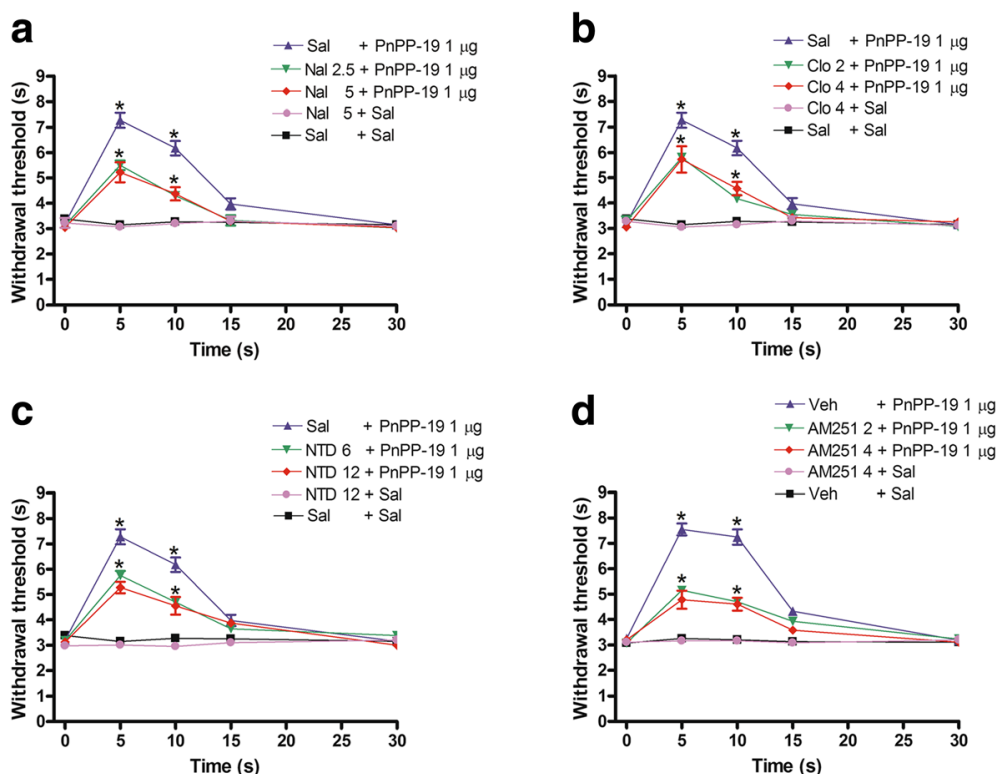

Fig. 2 Partial antagonism induced by intracerebroventricular administration of a naloxone, b clocinnamox, c naltrindole or $\mathbf{d}$ AM251 in the central antinociception induced by PnPP-19. Naloxone (Nal; 2.5 and $5 \mu \mathrm{g}$ ), clocinnamox (Clo; 2 and $4 \mu \mathrm{g}$ ), naltrindole (NTD; 6 and $12 \mu \mathrm{g}$ ) or AM251 (2 and $4 \mu \mathrm{g}$ ) was administered 1 min prior to PnPP-19 injection ( $1 \mu \mathrm{g}$ ). These antagonists did not significantly modify the nociceptive threshold in the control group. Each line represents the mean \pm SEM for four mice per group. *Significant difference compared to the control group (ANOVA + Bonferroni's test). Sal: saline (0.5\% of Evans Blue); Veh: vehicle (20\% DMSO in saline $0.5 \%$ of Evans Blue)

inhibitor bestatin, the anandamide amidase inhibitor MAFP and the anandamide uptake inhibitor VDM11 to verify the possible involvement of the endogenous opioid and cannabinoid systems on PnPP-19-induced antinociception.

In this experiment the PnPP-19 dose of $0.5 \mu \mathrm{g}$, instead of $1 \mu \mathrm{g}$, was employed to allow the observation of the potentiation effect that the selected inhibitors could induce. Therefore, at this time the ability of the aforementioned inhibitors to potentiate a lower dose of PnPP-19 $(0.5 \mu \mathrm{g})$ was tested. Bestatin (20 $\mu \mathrm{g}$, Fig. 4a), MAFP $(0.2 \mu \mathrm{g}$, Fig. 4b) and VDM11 (4 $\mu \mathrm{g}$, Fig. 4c) enhanced the antinociception induced by a low dose of PnPP-19 (0.5 $\mu \mathrm{g})$. No significant modification of the nociceptive threshold was observed when bestatin, MAFP, VDM11 or vehicle were injected alone.

\section{Discussion}

Spider venoms have been used as a potential source of new compounds with specific pharmacological properties. Some peptides extracted from the venom of the spider Phoneutria nigriventer have been suggested as potential sources of drugs for pain treatment. For instance, PnTx3-3 ( $\omega$ ctenitoxin Pn2a) and Pho1 $\beta$ induce an antinociceptive effect in neuropathic pain models [4, 5]. More recently, we have shown that the synthetic peptide, PnPP-19, firstly characterized as a potentiator of erectile function, also produces antinociception in rats when peripherally injected [1, 17]. We also showed that this peripheral effect involves inhibition of neutral endopeptidase (NEP) (EC 3.4.24.11), and activation of $\mathrm{CB}_{1}, \mu$ - and $\delta$-opioid receptors [17]. Therefore, the next issue to be investigated was whether PnPP-19 presents a possible central activity on nociception.

Our results demonstrate a dose-dependent central antinociceptive effect induced by PnPP-19 in the tailflick test and reinforce the role of PnPP-19 as an analgesic drug candidate. We also investigated the possible participation of opioids and cannabinoids in the PnPP19-induced central antinociception. In recent years, our group has shown the relationship between opioid and cannabinoid systems, as well as their involvement in the central and peripheral action mechanisms of different substances [9, 10, 15, 21, 22].

Interestingly, it was demonstrated that some animal toxins induce antinociception by activation of the opioid system. The analgesic effects of the neurotoxin from the king cobra's venom (Ophiophagus hannah), the crude venom of the snake Micrurus lemniscatus and two scorpion toxins, AmmVIII (Androctonus mauritanicus mauritanicus) and LqqIT2 (Leiurus quinquestriatus quinquestriatus), were antagonized by administration of the opioid receptor antagonist naloxone [16, 23, 24]. Given the aforementioned information about the participation of opioids as at least part of the action mechanism of some toxins, and especially considering our previous results with PnPP-19 on peripheral nervous system, our experiments showed that naloxone partially inhibits the central antinociception induced by PnPP-19. As observed with a higher dose, a 


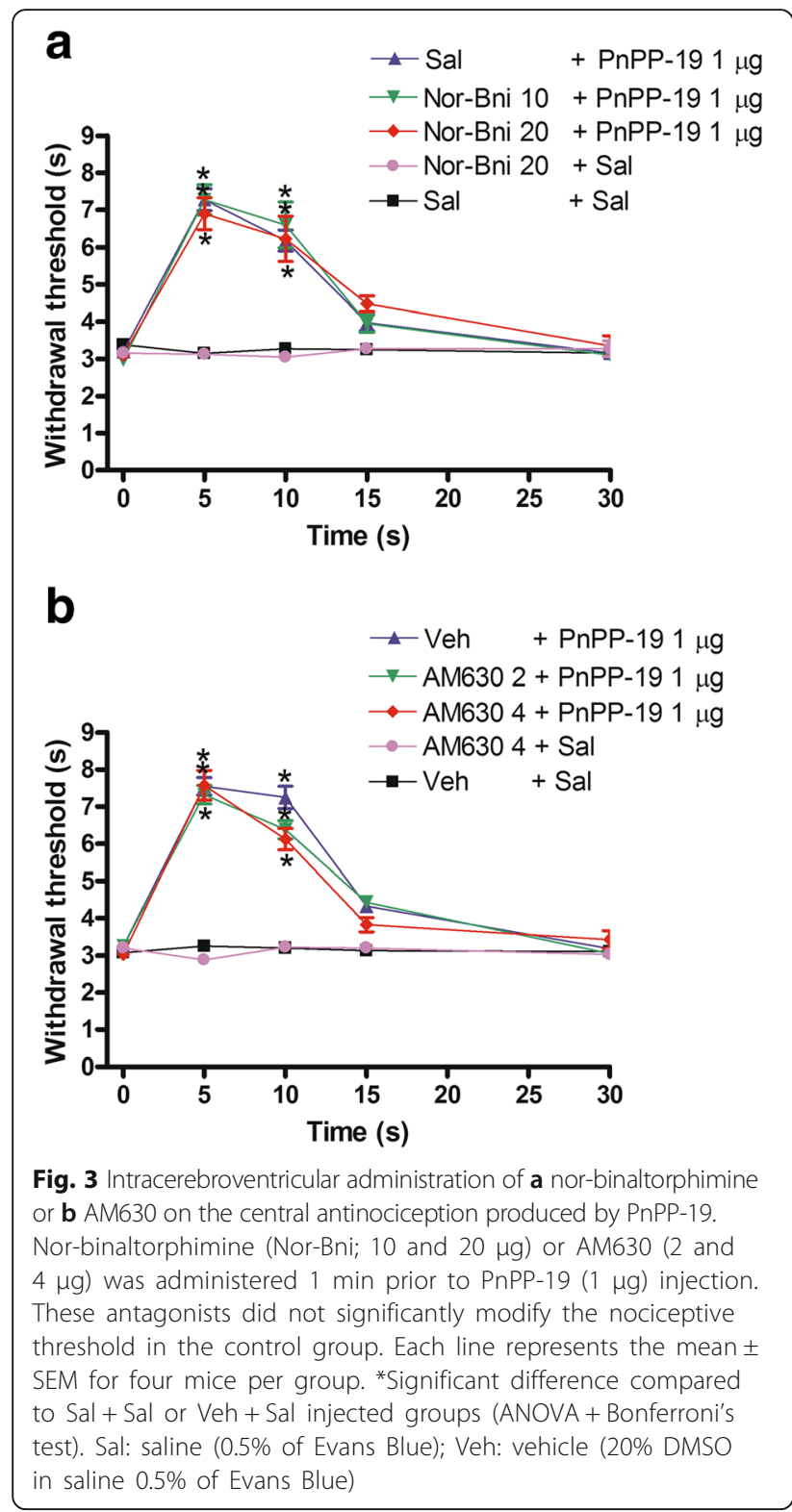

complete antagonism was not observed. This is the first report of opioid participation in the central antinociceptive mechanism of peptides derived from toxins purified from Phoneutria nigriventer venom.

Since naloxone interacts with $\mu$-, $\kappa$ - and $\delta$-opioid receptors, highly selective antagonists were used to clarify which receptor subtype would be involved in the central antinociceptive effect of PnPP-19. Clocinnamox is an irreversible $\mu$-opioid receptor antagonist with $K_{i}$ values of $0.7,1.9$ and $5.7 \mathrm{nM}$ for mouse $\mu$-, $\delta$ - and $\kappa$-opioid receptors, respectively [25]. Naltrindole has 223- and 346 -fold greater activity for $\delta$ - than for $\mu$ - and $\kappa$-opioid receptors, whereas nor-binaltorphimine shows 27 - to 29 -fold less potency, respectively, for $\mu$ and $\delta$ binding sites compared with $\mathrm{K}$ receptors binding sites $[26,27]$.

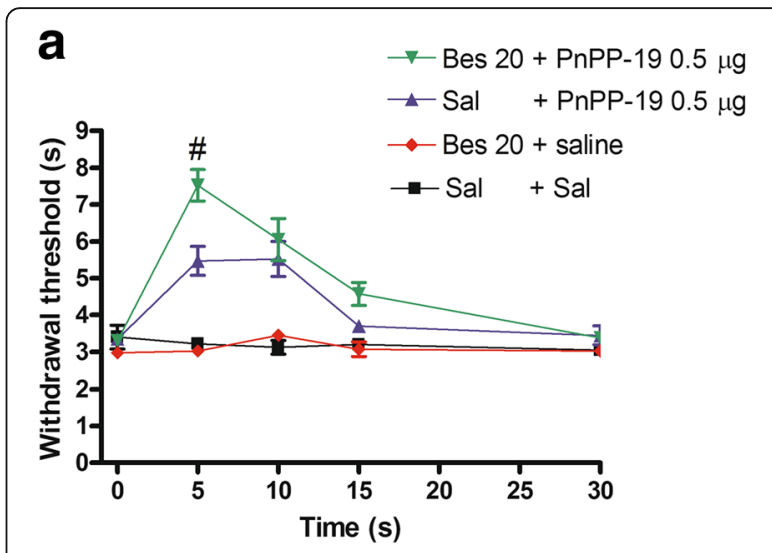

b
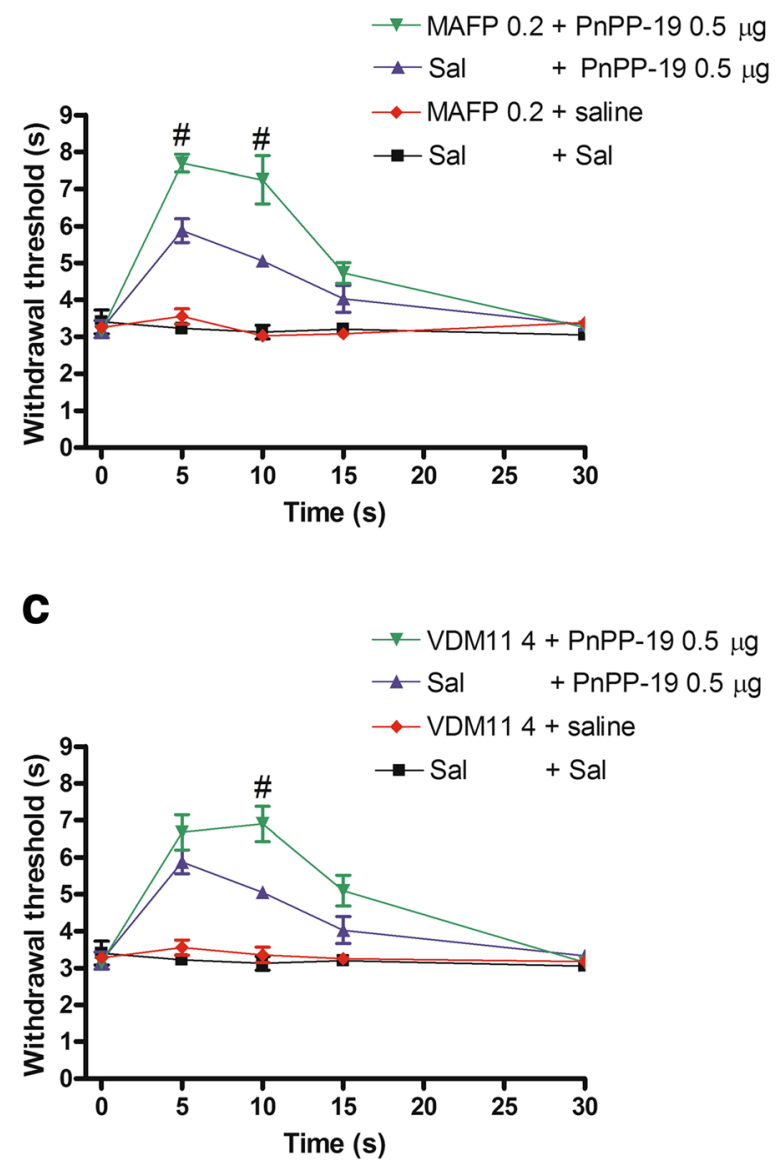

Fig. 4 Potentiation of PnPP-19-induced antinociception by a bestatin, b MAFP or c VDM11. The bestatin (Bes; $20 \mu \mathrm{g}$ ), MAFP $(0.2 \mu \mathrm{g}$ ) or VDM11 $(4 \mu \mathrm{g})$ was administered 1 min prior to PnPP-19 $(0.5 \mu \mathrm{g})$ injection. These drugs administered alone did not induce any effect. Each line represents the mean \pm SEM for four mice per group. \#Significant difference compared to the Sal + PnPP-19-injected group (ANOVA + Bonferroni' test; $p<0.05)$. Sal: saline $(0.5 \%$ of Evans Blue)

Our results showed that clocinnamox and naltrindole, but not nor-binaltorphimine, partially antagonized PnPP-19-induced central antinociception, suggesting 
the participation of $\mu$ - and $\delta$-opioid receptors in this effect, which is in accordance with previous findings on the peripheral nervous system [17]. In contrast, א-opioid receptors appear to be involved in the antinociception induced by the crude venom of the snake Micrurus lemniscatus and the potent analgesic peptide isolated from the venom of the South American rattlesnake Crotalus durissus terrificus, crotalphine $[24,28]$. The antinociception of crotalphine was blocked by pretreatment with selective antagonist of $\mathrm{\kappa}$ opioid receptors [28], an effect not observed in the present study when we tried to inhibit the antinociception of PnPP-19 by administration of a selective antagonist of the same opioid receptor.

In relation to opioid signaling, we applied the strategy of increasing the opioidergic system potency through opioid peptide catabolism inhibition. We observed that the administration of the aminopeptidase inhibitor bestatin significantly enhanced the central antinociception produced by a low dose of PnPP-19, providing evidence of the involvement of endogenous opioids in this effect. In vivo, enkephalins appear to be degraded by enzymes such as neutral endopeptidase and aminopeptidase [29]. Other opioid peptides, such as endorphin and dynorphin, appear to be resistant to neutral endopeptidase catabolism and, to a lesser extent, aminopeptidase [30].

Several studies have demonstrated reciprocal interactions between opioid and cannabinoid systems, suggesting a common underlying mechanism. For example, the cannabinoid $\Delta^{9}$-THC produces an increase in morphine antinociception by inducing the release of the endogenous opioid dynorphin [13]. On the other hand, the administration of the $C_{1}$ receptor antagonist AM251 inhibited morphine-induced antinociception $[9,15]$. The synergy in the analgesic effects of these compounds is attributed to a crosstalk between these two signaling pathways mediated by simultaneous activation of opioid and cannabinoid receptors [31].

Recently, it was shown that peripheral interactions between cannabinoid and opioid systems contribute to the antinociceptive effect of the peptide crotalphine [32]. These authors demonstrated that crotalphine-induced antinociception stimulates local release of dynorphin $\mathrm{A}$, which is dependent on $\mathrm{CB}_{2}$ receptor activation [32]. In contrast, we observed the participation of the $\mathrm{CB}_{1}$ receptor in PnPP-19induced central antinociception, and as previously reported, $\mu$ and $\delta$ opioids receptors are also involved [17].

It has been suggested that $\mathrm{CB}_{1}$ and $\mu$ - and $\delta$-opioid receptors form heterodimers [33]. These structures are necessary for the functioning of certain G-proteincoupled receptors, such as the $\mathrm{GABA}_{\mathrm{B}}$ receptor [34]. A previous study demonstrated the important role for the heterodimer $C_{1}-\delta$ in neuropathic pain where cortical functions of $\delta$ opioid receptors were altered [35]. On the other hand, $\mu$ opioid receptors and $\mathrm{CB}_{1}$ receptors form a functional heterodimer and may transmit a signal through a common $\mathrm{G}$ protein mechanism [36].

As a consequence of this work, the identification of the endocannabinoid involved in pain modulation was assessed indirectly by administration of pharmacological agents that regulate uptake or degradation of anandamide. This endocannabinoid is an agonist of $\mathrm{CB}_{1}$ and $\mathrm{CB}_{2}$ receptors, but presents greater affinity for the former [37, 38]. The results demonstrated that the anandamide amidase inhibitor MAFP and anandamide uptake inhibitor VDM11 increase the central antinociception produced by a low dose of PnPP-19, suggesting the release of endocannabinoids and subsequent activation of $\mathrm{CB}_{1}$ receptors.

\section{Conclusions}

In conclusion, our results show that PnPP-19 induces antinociception via the central nervous system and suggest that this effect is associated with the activation of $\mu-, \delta$ - opioid and $\mathrm{CB}_{1}$ cannabinoid receptors. The release of endogenous opioids and endocannabinoids that might be acting on these receptors appears to be involved in the antinociceptive mechanism of the peptide. The results of this work contribute to elucidating the central antinociceptive effect of PnPP-19; however, more research is required to elucidate the interaction between opioid and cannabinoid systems in this effect.

In summary, our data together with the results obtained in the peripheral nervous system [17] show that PnPP-19 has a broad antinociceptive effect and thus constitutes a potential lead compound for the development of novel analgesic drugs.

\section{Acknowledgements}

Thanks are due to the Center for the Study of Venoms and Venomous Animals (CEVAP) of UNESP for enabling the publication of this paper (Edital Toxinologia CAPES no. 063/2010, Process no. 230.38.006285/201121, AUXPE Toxinologia 1219/2011).

\section{Funding}

Fellowships were awarded to authors by the following Brazilian agencies: the State of Minas Gerais Research Foundation (FAPEMIG), the Coordination for the Improvement of Higher Education Personnel (CAPES), the National Council for Scientific and Technological Development (CNPq) and the National Institute of Science and Technology on Toxins (INCTTOX). This work was also supported by the Edital Toxinologia CAPES no. 063/2010, Process no. 230.38.006280/2011-07, AUXPE Toxinologia 1810/2011.

\section{Authors' contributions}

ACNF and DFP performed the research, analyzed data and wrote the first draft of the manuscript. AMP, IDGD and MEL designed research, contributed with essential reagents or tools and reviewed the paper. All authors read and approved the final manuscript.

\section{Competing interests}

The authors declare that they have no competing interests.

\section{Ethics approval}

The algesimetric protocol was approved by the Committee for Ethics in Animal Experimentation (CETEA) of UFMG, under the protocol number $131 / 2014$. 


\section{Author details}

'Departmento de Farmacologia, Instituto de Ciências Biológicas,

Universidade Federal de Minas Gerais (UFMG), Belo Horizonte, MG, Brazil. ${ }^{2}$ Departamento de Bioquímica e Imunologia, Instituto de Ciências Biológicas, Universidade Federal de Minas Gerais (UFMG), Av. Antônio Carlos, 6627, Belo Horizonte, MG CEP 31.270.901, Brazil.

Received: 27 July 2016 Accepted: 30 November 2016

\section{Published online: 21 December 2016}

\section{References}

1. Silva CN, Nunes KP, Torres FS, Cassoli JS, Santos DM, Almeida FM, et al. PnPP-19, a synthetic and nontoxic peptide designed from a Phoneutria nigriventer toxin, potentiates erectile function via NO/cGMP. J Urol. 2015; 194(5):1481-90. doi:10.1016/j.juro.2015.06.081.

2. King GF, Gentz MC, Escoubas P, Nicholson GM. A rational nomenclature for naming peptide toxins from spiders and other venomous animals. Toxicon. 2008;52(2):264-76. doi:10.1016/j.toxicon.2008.05.020.

3. Cordeiro MN, Diniz CR, Valentim AC, von Eickstedt VR, Gilroy J, Richardson $M$. The purification and amino acid sequences of four Tx2 neurotoxins from the venom of the Brazilian 'armed' spider Phoneutria nigriventer (Keys). FEBS Lett. 1992;310(2):153-6.

4. Dalmolin GD, Silva CR, Rigo FK, Gomes GM, Cordeiro MN, Richardson M, et al. Antinociceptive effect of Brazilian armed spider venom toxin Tx33 in animal models of neuropathic pain. Pain. 2011;152(10):2224-32. doi:10.1016/j.pain.2011.04.015.

5. de Souza AH, Castro Jr CJ, Rigo FK, de Oliveira SM, Gomez RS, Diniz DM, et al. An evaluation of the antinociceptive effects of Pha1 $\beta$, a neurotoxin from the spider Phoneutria nigriventer, and $\omega$-conotoxin MVIIA, a cone snail Conus magus toxin, in rat model of inflammatory and neuropathic pain. Cell Mol Neurobiol. 2013;33(1):59-67. doi:10.1007/s10571-012-9871-x.

6. Manzaneres J, Corchero J, Romero J, Fernandez-Ruiz JJ, Ramos JA, Fuentes JA. Pharmacological and biochemical interactions between opioids and cannabionoids. Trends Pharmacol Sci. 1999;20(7):287-94.

7. Massi P, Vaccani A, Romorini S, Parolaro D. Comparative characterization in the rat of the interaction between cannabinoids and opiates for their immunosopressive and analgesic effects. J Neuroimmunol. 2001;117:116-24.

8. Varvel SA, Cishewicz DL, Lichtman AH. Interactions between cannabinoids and opioids. In: Wenger T, editor. Recent advances in pharmacology and physiology of cannabinoids. Cochin: Kerala Press; 2004. p. 157-82.

9. da Fonseca PD, Klein A, de Castro PA, da Fonseca Pacheco CM, de Francischi JN, Duarte ID. The mu-opioid receptor agonist morphine, but not agonists at delta-or kappa-opioid receptors, induces peripheral antinociception mediated by cannabinoid receptors. Br J Pharmacol. 2008;154(5):1143-9. doi:10.1038/bjp.2008.175.

10. Pacheco DF, Romero TR, Duarte ID. Central antinociception induced by ketamine is mediated by endogenous opioids and $\mu$ - and $\delta$-opioid receptors. Brain Res. 2014;1562:69-75. doi:10.1016/j.brainres.2014.03.026.

11. Bidaut-Russell M, Devane WA, Howlett AC. Cannabinoid receptors and modulation of cyclic AMP accumulation in the rat brain. J Neurochem. 1990;55(1):21-6.

12. Childers SR. Opioid receptor-coupled second messengers systems. Life Sci. 1991;48(21):1991-2003.

13. Welch SP, Eads M. Synergistic interactions of endogenous opioids and cannabinoid systems. Brain Res. 1999;848(1-2):183-90.

14. Finn DP, Beckett SR, Roe CH, Madjd A, Fone KC, Kendall DA, et al. Effects of coadministration of cannabinoids and morphine on nociceptive behaviour, brain monoamines and HPA axis activity in a rat model of persistent pain. Eur J Neurosci. 2004;19(3):678-86.

15. Pacheco DF, Klein A, Perez AC, Pacheco CM, Francischi JN, Reis GM, et al. Central antinociception induced by $\mu$-opioid receptor agonist morphine, but not delta- or kappa-, is mediated by cannabinoid CB1 receptor. $\mathrm{Br} J$ Pharmacol. 2009;158(1):225-31. doi:10.1111/j.1476-5381.2009.00310.

16. Martin-Eauclaire MF, Abbas N, Sauze N, Mercier L, Berge-Lefranc JL, Condo J, et al. Involvement of endogenous opioid system in scorpion toxin-induced antinociception in mice. Neurosci Lett. 2010;482(1):45-50. doi:10.1016/j. neulet.2010.06.090

17. Freitas AC, Pacheco DF, Machado MF, Carmona AK, Duarte ID, de Lima ME. PnPP-19, a spider toxin peptide, induces peripheral antinociception through opioid and cannabinoid receptors and inhibition of neutral endopeptidase. Br J Pharmacol. 2016;173(9):1491-501. doi:10.1111/bph.13448.
18. D'Amour FE, Smith DL. A method for determining loss of pain sensation. J Pharmacol Exp Ther. 1941;72(1):74-9.

19. Le Bars D, Gozariu M, Cadden SW. Animal models of nociception. Pharmacol Rev. 2001;53(4):597-652.

20. Haley TJ, McCormick WG. Pharmacological effects produced by intracerebral injection of drugs in the conscious mouse. Br J Pharmacol Chemother. 1957;12(1):12-5

21. Silva LC, Romero TR, Guzzo LS, Duarte ID. Participation of cannabinoid receptors in peripheral nociception induced by some NSAIDs. Braz I Med Biol Res. 2012;45(12):1240-3.

22. Romero TR, Pacheco DF, Duarte ID. Xylazine induced central antinociception mediated by endogenous opioids and $\mu$-opioid receptor, but not $\delta$-or k-opioid receptors. Brain Res. 2013;1506:58-63. doi:10.1016/j.brainres.2013.02.030.

23. Pu XC, Wong PT, Gopalakrishnakone P. A novel analgesic toxin (hannalgesin) from the venom of king cobra (Ophiophagus hannah). Toxicon. 1995:33(11):1425-31.

24. Leite dos Santos GG, Casais e Silva LL, Pereira Soares MB, Villarreal CF. Antinociceptive properties of Micrurus lemniscatus venom. Toxicon. 2012; 60(6):1005-12

25. Burke TF, Woods JH, Lewis JW, Medzihradsky F. Irreversible opioid antagonist effects of clocinnamox on opioid analgesia and mu receptor binding in mice. J Pharmacol Exp Ther. 1994;271(2):715-21.

26. Portoghese PS, Sultana M, Takemori AE. Design of peptidomimetic delta opioid receptor antagonists using the message-address concept. J Med Chem. 1990:33(6):1714-20

27. Rothman RB, Bykov V, Reid A, de Costa BR, Newman AH, Jacobson AE, et al. A brief study of the selectivity of norbinaltorphimine, (-)-cyclofoxy, and (+)-cyclofoxy among opioid receptor subtypes in vitro. Neuropeptides. 1988; 12(3):181-7.

28. Konno K, Picolo G, Gutierrez VP, Brigatte P, Zambelli VO, Camargo AC, et al. Crotalphine, a novel potent analgesic peptide from the venom of the South American rattlesnake Crotalus durissus terrificus. Peptides. 2008; 29(8):1293-304. doi:10.1016/j.peptides.2008.04.003.

29. Roques BP, Noble F, Daugé V, Fournié-Zaluski MC, Beaumont A. Neutral endopeptidase 24.11: structure, inhibition and experimental and clinical pharmacology. Pharmacol Rev. 1993;45(1):87-146.

30. Nieto MM, Wilson J, Walker J, Benavides J, Fournié-Zaluski MC, Roques BP, et al. Facilitation of enkephalins catabolism inhibitor-induced antinociception by drugs classically used in pain management. Neuropharmacology. 2001; 41(4):496-506.

31. Cichewicz DL. Synergistic interactions between cannabinoid and opioid analgesics. Life Sci. 2004;74(11):1317-24.

32. Machado FC, Zambelli VO, Fernandes AC, Heimann AS, Cury Y, Picolo G. Peripheral interactions between cannabinoid and opioid systems contribute to the antinociceptive effect of crotalphine. Br J Pharmacol. 2014;171(4): 961-72. doi:10.1111/bph.12488

33. Rios C, Gomes I, Devi LA. mu opioid and CB1 cannabinoid receptor interactions: reciprocal inhibition of receptor signaling and neuritogenesis. Br J Pharmacol. 2006;1 148(4):387-95.

34. Ong J, Kerr DI. Recent advances in GABAB receptors: from pharmacology to molecular biology. Acta Pharmacol Sin. 2000;21(2):111-23.

35. Bushlin I, Gupta A, Stockton SD, Miller LK, Devi LA. Dimerization with cannabinoid receptors allosterically modulates delta opioid receptor activity during neuropathic pain. PLoS One. 2012;7(12):e49789. doi:10.1371/journal.pone.0049789.

36. Hojo M, Sudo Y, Ando Y, Minami K, Takada M, Matsubara T, et al. mu-Opioid receptor forms a functional heterodimer with cannabinoid CB1 receptor: electrophysiological and FRET assay analysis. J Pharmacol Sci. 2008;108(3):308-19.

37. Howlett AC, Barth F, Bonner TI, Cabral G, Casellas P, Devane WA, et al. International Union of Pharmacology XXVII. Classification of cannabinoid receptors. Pharmacol Rev. 2002;54(2):161-202.

38. Hohmann AG, Suplita RL. Endocannabinoid mechanisms of pain modulation. AAPS J. 2006:8(4):E693-708. 